\title{
Perceptual context effects on line discriminations by monkeys as measured by choice response accuracy and eye movements
}

\author{
ALLAN M. SCHRIER \\ Brown University, Providence, Rhode Island
}

\begin{abstract}
Stumptailed monkeys (Macaca arctoides) were given two two-choice line-discrimination problems in which the lines were presented either alone or embedded in a patterned context that was the same in all cases. When the stimuli were a left- and a right-tilting line, the addition of the context significantly improved performance, as measured by frequency of correct choice responses. It also decreased choice response latency, duration of visual fixations, and frequency of scanning back and forth between the two stimuli. When the stimuli were a horizontal and a vertical line, the addition of the context had the opposite effect on all the performance measures. These results are very similar to those found with adult and infant humans when given the same stimuli. They suggest that the pattern perception of monkeys, like that of humans, involves top-down or holistic processing of incoming visual information.
\end{abstract}

In recent years, stimulated by a study by Weisstein and Harris (1974), there has been considerable interest in the effects of contextual information on the perception by humans of relatively simple visual targets. Weisstein and Harris reported that human subjects identified a tachistoscopically flashed line segment more accurately when it was embedded in a context which, together with the line segment, formed a pattern that appeared unitary and three-dimensional than when the line and context formed visual displays that did not appear so. Weisstein and Harris named this phenomenon the "object superiority effect." This appears to be analogous to the word superiority effect (Wheeler, 1970), in which the perception of individual letters is better in the context of a word than in a meaningless string of letters.

There has been some debate about whether a threedimensional appearance is a necessary condition for perceptual context effects when the type of contexts that Weisstein and Harris used are employed (Enns \& Prinzmetal, 1984; Lanze, Weisstein, \& Harris, 1982). However, a number of experiments (Bomba, Eimas, Siqueland, \& Miller, 1984; Earhard, 1980; Pomerantz, Sager, \& Stoever, 1977; Schendel \& Shaw, 1976; Williams \& Weisstein, 1978) have now shown that identification or discrimination of line segments and other simple stimuli can be improved by the addition of a context that creates a configuration that is clearly only twodimensional in appearance. Since a three-dimensional ap-

This research was supported by National Science Foundation Grants BNS82-01241 and BNS85-19469. I would like to thank Lisa A. Panzini for testing most of the animals and for her many other contributions to the research, and Peter Eimas, Judith Schrier, and Paul Quinn for making many helpful comments during the preparation of this report. Requests for reprints should be addressed to Allan M. Schrier, Psychology Department, Brown University, Providence, RI 02912. pearance was not a factor in these experiments, the enhancement of performance obtained in them will be referred to here as a "positive perceptual context effect." There is also evidence that the addition of a context can produce a decrement in identification or discrimination of such stimuli (Earhard, 1980; Earhard \& Armitage, 1980; Enns \& Prinzmetal, 1984; Pomerantz et al., 1977); this is referred to here as a "negative perceptual context effect." The interest in perceptual context effects stems in part from the fact that they appear to support theories that assume that pattern perception involves top-down processing of information or processing of emergent complex features rather than analysis of simple features (McClelland \& Miller, 1979; Navon, 1977; Pomerantz, 1981; Pomerantz et al., 1977). The processing of wholes, according to such theories, cannot be predicted from the processing of the isolated elements (such as the line segments used in some of the context effect studies).

Although there is a great deal of evidence that visual sensory capacities of Old World monkeys (such as rhesus, cynomolgus, and stumptailed macaques) are very similar to those of humans (DeValois \& Jacobs, 1971; Fobes \& King, 1982), there is relatively little data on their perceptual capacities (Riesen, 1982; Schrier, Povar, \& Schrier, 1979) that can be readily compared with the extensive data on human perceptual capacities and the underlying information processing mechanisms. Since perceptual context effects are a robust phenomenon in humans, including infants (Bomba et al., 1984; Quinn \& Eimas, in press), they would appear to provide a basis for a good comparative test of perception. One major purpose of the present study was to conduct such a test. Stumptailed monkeys were given two-choice linediscrimination problems in which the lines were presented either alone or embedded in a patterned context. In all cases, the context was the same for both the positive and 
negative stimulus constituting a problem, so that context per se never provided information that could be used to differentiate the stimuli. The study was carried out in an eye-movement recording situation, thereby permitting measures of some aspects of observing behavior in addition to the usual measures of choice response accuracy.

\section{METHOD}

\section{Subjects}

Eight stumptailed monkeys (Macaca arctoides) served as subjects. They were all adults, varying in age from 5.5 to 10.5 years. The amount of previous training in the apparatus differed, but all the animals had served in at least one experiment involving presentation of a series of dot-pattern discriminations and recording of eye movements (e.g., Schrier \& Povar, 1982). On test days, each animal received up to $50 \%$ of its daily food ration in the form of 190-mg banana-flavored whole diet food pellets (Noyes, Lancaster, $\mathrm{NH})$, which were used as reinforcers, and the balance of their food ration in their home cages.

\section{Apparatus}

The apparatus used in this experiment has been described before (Schrier \& Povar, 1982). The main components were a restraining chair, a stimulus presentation and response panel that was attached to the front of the restraining chair facing the animal, and devices for recording eye movements, using a corneal reflection technique. A computer and associated interface recorded the location of the corneal reflection and controlled and recorded experimental events.

The stimulus and response panel contained three $2.5-\mathrm{cm}$-diam circular response keys made of clear plastic, each with a 9-mmdiam hole in the center. These keys were arranged in the form of an inverted isosceles triangle approximately $31 \mathrm{~cm}$ in front of the animal's head. The key at the bottom of the inverted triangle is referred to as the "center" key, and the two at the top are referred to as the "side" keys. The center key was located 4 to $6 \mathrm{~cm}$ below the visual axis, depending on the configuration of the head and the placement of the head-restraining device for each subject

The discriminative stimuli were displayed on an oscilloscope, the face of which was mounted directly behind the stimulus-response panel. Patterns were generated by lighting small dots in a $6 \times 6$ matrix behind the holes in each of the side keys. Each matrix was approximately $4 \mathrm{~mm}$ square ( $46^{\prime}$ of visual angle), so the stimuli were much smaller than those usually used in studies of this type. The four pairs of dot patterns used as stimuli are illustrated in Figure 1. Two of the pairs composed the HV problem set, with one pair being the horizontal and vertical lines presented alone and the other being these stimuli with the noninformative context added. The remaining two pairs composed the OL problem set, with one pair being the left- and right-tilting oblique lines and the other being these stimuli with the noninformative context added.

\section{Procedure}

The subjects were given one test session per day, 5 days a week. Each test session consisted of 300 test trials that followed the 20 to 30 trials needed to align the corneal reflection equipment. During the initial alignment trials, the animals were given a discrimination problem consisting of a closed versus open square.

Each trial consisted of two phases, a "calibration" phase and a "discrimination" phase. The calibration phase involved only the center key, and functioned to maintain the spatial calibration of the eye-movement recording equipment from one trial to the next (Schrier \& Povar, 1978, 1982). The starting visual fixation point for all trials was a small spot of light that appeared behind the center key. The discrimination phase began immediately after the completion of the calibration phase. In this phase, the discriminative stimuli appeared behind the side keys for a maximum duration of
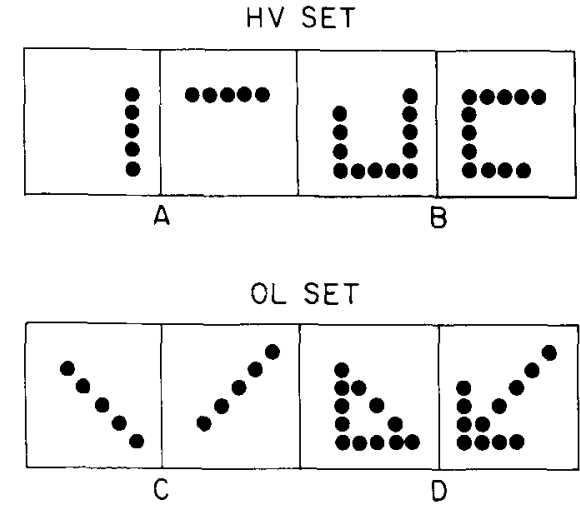

Figure 1. The four pairs of stimuli used in the present study. Pairs $A$ and $C$ composed the no-context problems in their respective problem sets, while Pairs $B$ and $D$ composed the context problems. Pairs $B$ and $D$ were created by adding the same right-angle dot pattern to each of the stimuli of Pairs $A$ and $C$. The small size of the stimuli and relatively large spatial separation between them on the stimulus and response panel made the difference in vertical displacement of the oblique lines virtually undetectable to the human eye and, judging by their performance, to the monkeys' eyes also.

$4 \mathrm{sec}$, which was almost always more than enough time for the choice response. Only this latter phase of each trial was used for data analysis. The intertrial interval was $5 \mathrm{sec}$.

Each animal was given one problem set at a time. The two problems (pairs of stimuli) in a problem set, the no-context problem and the corresponding context problem, were alternated from test trial to test trial throughout each test session. One of the pair of stimuli for each problem was positive and one was negative. For each animal, the differential stimulus that was positive in each problem set was always the same for the context and no-context problems. For example, if the vertical line was positive, it was so whether or not the context was present. If the subject pressed the response key behind which the positive stimulus was displayed, it received a food pellet. If the animal responded to the key behind which the negative stimulus was displayed, the trial was terminated and the intertrial interval began. The left-right positions of the positive and negative stimuli were randomized with no restrictions. The number of positive trials on each side was about the same for each condition from test session to test session.

Half of the animals received the HV problem set first; the remaining half received the OL problem set first. The animals were trained on each problem set until they reached a criterion of 19 correct responses in 20 consecutive trials two times in a row. In each case, they were then given an additional 100 postcriterion trials.

\section{RESULTS}

For purposes of data analysis, the trials on each problem were divided into five practice periods. The first three were successive thirds of the precriterion trials. The fourth was the 40 criterion trials, and the fifth was the following 100 postcriterion trials. Separate subjects $\times$ treatments analyses of variance were conducted on each of five sets of performance measures: percentage of correct responses, latency of the choice response, duration of the last visual fixation before the choice response, duration of visual fixations during a trial that preceded the last one, and number of scans per trial (that is, the number of shifts 
in fixation from one discriminative stimulus to the other). The treatments in each analysis were context condition (no context vs. context), problem set (HV vs. OL), and practice (periods 1-5). In order to produce distributions that were closer to normal, before any statistical analyses were performed, an arcsine transformation was carried out on all percentages and a log transformation was carried out on all latencies and fixation durations.

Accuracy of choice behavior under the major conditions of the experiment is summarized in Figure 2. The figure shows that context greatly enhanced accuracy of choice behavior when added to the oblique lines, but had the opposite effect when added to the horizontal and vertical lines. This difference in direction of the context effects was reflected in a highly significant context $x$ problem set interaction $[F(1,7)=31.5, p<.001]$. The context effects tended to decrease with practice, undoubtedly in part a ceiling effect, producing a significant context condition $\times$ problem set $\times$ practice interaction $[F(4,28)=3.46, p<.05]$. Separate analyses of variance on the data for each problem set showed that the negative context effect was highly significant $[F(1,7)=$ $70.1, \mathrm{p}<.001]$ but that the positive context effect fell just short of significance $[F(1,7)=4.55, p<.10]$. This last outcome was primarily the result of one of the 8 subjects' showing a relatively strong negative context effect for the OL problem set. As it happens, 2 additional animals were tested under the conditions described earlier, but were not included in the main analyses because they did not complete both problem sets, one the OL set and the other the HV set. The animal that completed the HV set showed the same strong negative context effect that the other 8 animals did; the animal that completed the $\mathrm{OL}$ set showed the same strong positive context effect that most of the other 8 did. Adding the latter animal's OL set data to that of the other 8 produced a clearly significant positive contrast effect $[F(1,8)=6.67, p<.05]$.

The effect of context on latency of the choice response and on the eye-movement measures is summarized in Table 1. As was the case with choice response accuracy, the direction of the effect, which was sizable in all cases except duration of fixations preceding the last, depended on the problem set. Latency and duration of fixations were longer and the number of scans per trial was greater for whichever problem was the more difficult in each problem set. This produced a significant problem set $\times$ context condition interaction in the case of latency $[F(1,7)=21.5$, $\mathrm{p}<.01]$, duration of the last fixation $[\mathrm{F}(1,7)=6.25$, $\mathrm{p}<.05]$, and number of scans $[\mathrm{F}(1,7)=28.2, \mathrm{p}<.01]$. The duration of the last fixation was significantly longer than that of preceding fixations $[F(1,7)=7.31, p<.05]$. Previous data for monkeys suggest that the last fixation reflects choice response decision time as well as time to prepare for and execute the choice response (Schrier, 1983).

\section{DISCUSSION}

The present study clearly demonstrated both negative and positive context effects on accuracy of performance, speed of performance, and visual observing behavior of monkeys when given line-discrimination problems. Adding a redundant context to a horizontal versus vertical line discrimination decreased accuracy of choice behavior and increased the choice response latency, the number of visual scans per trial, and the duration of the last fixation on a trial. Adding the same redundant context to an oblique-lines discrimination had the opposite effect on all of these performance measures. These results are especially striking in that they correspond well with results

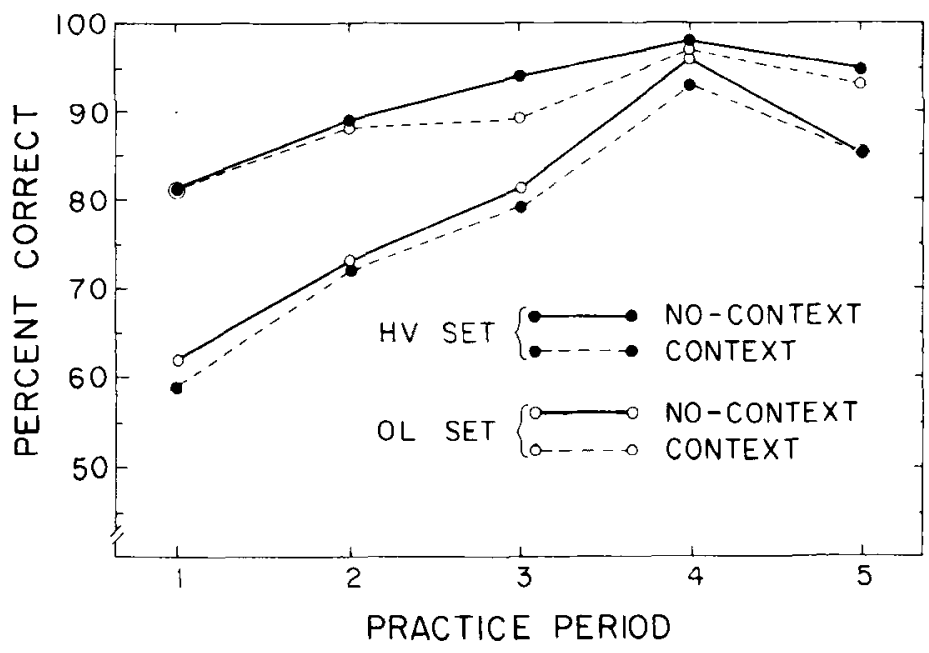

Figure 2. The percentage of correct responses by the group of monkeys on the no-context and context problems of each problem set during each of the five practice periods. 
Table 1

Mean Choice Response Latency (Latency), Duration of All Visual Fixations Preceding the Last One of a Trial (All But Last), Duration of the Last Visual Fixation of a Trial (Last), and Number of Scans Per Trial

\begin{tabular}{clrrrr}
\hline \multirow{2}{*}{ Problem Set } & $\begin{array}{c}\text { Context } \\
\text { Condition }\end{array}$ & Latency & $\begin{array}{c}\text { All But } \\
\text { Last }\end{array}$ & Last & Scans \\
\hline \multirow{2}{*}{ HV } & No-Context & 785 & 266 & 335 & 0.77 \\
& Context & 1,016 & 283 & 365 & 1.46 \\
\multirow{2}{*}{ OL } & No-Context & 979 & 291 & 368 & 1.23 \\
& Context & 844 & 283 & 337 & 0.99 \\
\hline
\end{tabular}

Note-Response latency and duration of fixations are shown in milliseconds.

obtained in work with humans in which the stimuli were the same or similar to those used here. In a study by Pomerantz et al. (1977) with adult humans, adding a context that was essentially the same as the one used here produced a large decrease in time to discriminate between left- and right-tilting oblique lines. On the other hand, adding various noninformative contexts to a horizontal versus vertical line discrimination, although none were the same as those used here, produced large increases in discrimination time in two instances and no significant change in a third. Using virtually identical stimuli, results that were similar to the present ones were also obtained by Quinn and Eimas (in press) in an experiment with human infants.

The only other test with animals for perceptual context effects of the type being considered here was conducted by Cheng and Blough (Blough, 1984), who used pigeons. Although they used the same set of stimuli that was used in the present study, they found positive context effects in all cases. Their procedures differed in a number of ways from those used here, but the differences do not appear to be any more striking than the many differences in procedure between the present study and those with humans.

In general terms, the present results suggest that the pattern perception of monkeys, like that of human adults and infants, involves top-down or global information processing (McClelland \& Miller, 1979; Navon, 1977) or processing of emergent complex features (Pomerantz et al., 1977), rather than simple-feature-by-simple-feature processing. The results obtained with the oblique lines are particularly pertinent to this conclusion. Mirror-image pairs of stimuli, such as the oblique lines used here, are typically more difficult for humans and animals to discriminate than are non-mirror-image pairs (Appelle, 1972). Adding the redundant context has the effect of converting the oblique lines to a non-mirror-image pair, at least if we assume that the processing involves more than a feature-by-feature analysis. It is unlikely that the mirrorimage condition is a necessary one for positive context effects in the discrimination of straight lines or other relatively simple stimuli (Pomerantz et al., 1977), and it clearly is not necessary for demonstrating such effects when the broader range of stimuli used in the various studies in the relevant literature is considered.
Taken in isolation, the results with the HV set could perhaps be equally well explained in terms of analysis of simple features. For example, the context condition involved adding, among other things, a vertical component to the horizontal line and a horizontal component to the vertical line, thus increasing the similarity of the two stimuli. However, it would also have to be assumed that the processing of the context stimuli was different in the case of the $\mathrm{HV}$ and $\mathrm{OL}$ sets, an assumption that there seems no reason to make. Also, in the study by Pomerantz et al., of the two contexts that produced marked negative effects when added to a horizontal versus vertical line discrimination, one could be described as increasing the similarity of the pair of stimuli in the same way that context did here, but the other very clearly could not be so described.

Since performance on the no-context problem of the horizontal versus vertical lines problem set was relatively good early in learning and left little room for improvement near the end of learning, it might be difficult to find any context that would improve performance on it. However, the results with this problem set were clearly not reflecting a ceiling effect, since all of the animals showed considerably poorer performance on the context version of the problem than they did on the no-context version. Negative context effects, as already mentioned, have been reported before this and can be interpreted in the same terms as the positive effects (Pomerantz et al., 1977). Not all contexts can be expected to create more discriminable or more easily identifiable stimuli, whether the processing begins globally or involves emergent features. However, one problem is that it is difficult to predict the direction of the effect. Recently, Enns and Prinzmetal (1984) found evidence that suggests that the direction of the effect in humans depends on the relative ease of discrimination of the no-context stimuli as compared with that of context stimuli, as measured independently by ratings of intrapair stimulus similarity. Positive context effects, as measured by the proportion of correct identifications, were obtained with context stimuli that had been rated as less similar to one another (and, thus, presumably easier to discriminate between) than the corresponding no-context stimuli had been. No context effects were found with context stimuli that had been rated as about as similar to one another as the corresponding no-context stimuli. Presumably, negative context effects would have been obtained had they used context stimuli that had been rated as considerably more similar to one another than the corresponding no-context stimuli. Similarity of the stimuli composing the problems was not measured independently of the context effects in the present study, so the results have no direct bearing on the account suggested by the Enns and Prinzmetal findings. However, the present results, as well as some previous results with humans (Pomerantz et al., 1977), are consistent with this account in that they suggest that a positive effect is more likely when the no-context task is relatively hard and a negative effect when it is relatively easy, and that this is 
not simply a matter of either a floor or a ceiling on performance (Pomerantz et al., 1977).

Whatever the exact basis for the context effects, the differences that context made in the ease of discrimination, as measured by both speed and accuracy of the choice response, were also reflected in striking differences in visual observing behavior. Rarely, in the many studies conducted in this laboratory in a variety of discrimination learning situations (Schrier, 1983), have the eyemovement measures been as clearly and consistently influenced by problem difficulty as they were in the present case. This attests further to the potency of the context variable. Resolution of the eye-movement measurement system used here was not great enough to allow inferences about the details of the relatively small stimuli that the animals were observing, and, hence, did not aid in drawing any finer conclusions about the nature of the processing involved. The present eye-movement results are consistent with prior findings in this laboratory that duration of individual fixations preceding the last one of a trial are relatively insensitive to a variety of experimental variables in discrimination learning contexts, in contrast to the duration of the last fixation and amount of scanning (Schrier, 1983).

\section{REFERENCES}

APPELLE, S. (1972). Perception and discrimination as a function of stimulus orientation: The "oblique effect" in man and animals. Psychological Bulletin, 78, 266-278.

Blough, D. S. (1984). Form recognition in pigeons. In H. L. Roitblat, T. G. Bever, \& H. S. Terrace (Eds.), Animal cognition (pp. 277 289). Hillsdale, NJ: Erlbaum.

Bomba, P. C., Eimas, P. E., Siqueland, E. R., \& Miller, J. L. (1984). Contextual effects in infant visual perception. Perception, 13, 369-376.

DeVAlois, R. L., \& Jacobs, G. H. (1971). Vision. In A. M. Schrier \& F. Stollnitz (Eds.), Behavior of nonhuman primates (Vol. 3. pp. 107-157). New York: Academic Press.

EARHARD, B. (1980). The line-in-object superiority effect in perception: It depends on where you fix your eyes and what is located at the point of fixation. Perception \& Psychophysics, 28, 9-18.

EARHARD, B., \& ARMITAGE, R. (1980). From an object-superiority effect to an object-inferiority effect with movement of the fixation point. Perception \& Psychophysics, 28, 369-376.
Enns, J. T., \& Prinzmetal, W. (1984). The role of redundancy in the object-line effect. Perception \& Psychophysics, 35, 22-32.

FoBES, J. L., \& KING, J. E. (1982). Vision: The dominant primate modality. In J. L. Fobes \& J. E. King (Eds.), Primate behavior (pp. 219243). New York: Academic Press.

Lanze, M., Weisstein, N., \& Harris, J. R. (1982). Perceived depth vs. structural relevance in the object superiority effect. Perception \& Psychophysics, 31, 376-382.

McClelland, J. L., \& Millek, J. (1979). Structural factors in figure perception. Perception \& Psychophysics, 26, 221-229.

Navon, D. (1977). Forest before trees: The precedence of global features in visual perception. Cognitive Psychology, 9, 353-383.

Pomerantz, J. R. (1981). Perceptual organization in information processing. In M. Kubovy \& J. R. Pomerantz (Eds.), Perceptual organization (pp. 141-180). Hillsdale, NJ: Erlbaum.

Pomerantz, J. R., Sager, L. C., \& Stoever, R. J. (1977). Perception of wholes and of their component parts: Some configural superiority effects. Journal of Experimental Psychology: Human Perception \& Performance, 3, 422-435.

Quinn, P. C., \& Eimas, P. D. (in press). Pattern-line effects and units of visual processing in infants. Infant Behavior \& Development.

Riesen, A. H. (1982). Primate perceptual processes. In J. L. Fobes \& J. E. King (Eds.), Primate behavior (pp. 271-286). New York: Academic Press.

SChendel, J. D., \& Shaw, P. (1976). A test of the generality of the word-context effect. Perception \& Psychophysics, 19, 383-393.

SCHRIER, A. M. (1983). Eye movements of stumptailed monkeys during discriminative performance: An overview. International Journal of Primatology, 4, 373-381.

Schrier, A. M., \& Povar, M. L. (1978). Eye movements of monkeys during learning set formation. Science, 199, 1362-1364.

Schrier, A. M., \& Povar, M. L. (1982). Eye movements of monkeys during discrimination learning: Role of visual scanning. Journal of Experimental Psychology: Animal Behavior Processes, 8, 33-48.

Schrier, A. M., Povar, M. L., \& Schrier, J. E. (1979). Effects of goodness and other properties of patterns on discriminative performance of monkeys. Perception \& Psychophysics, 25, 215-220.

Weisstein, M., \& Harris, C. S. (1974). Visual detection of line segments: An object superiority effect. Science, 186, 752-755.

WheEler, D. D. (1970). Processes in word recognition. Cognitive Psychology, 1, 59-85.

Williams, A., \& Weisstein, N. (1978). Line segments are perceived better in a coherent context than alone: An object-line effect in visual perception. Memory \& Cognition. 6. 85-90.

(Manuscript received May 24. 1985:

revision accepted for publication September 23, 1985.) 